Article

\title{
Antimicrobial Potential of Silver Nanoparticles Synthesized Using Medicinal Herb Coptidis rhizome
}

\author{
Garima Sharma ${ }^{\dagger}$, Ju-Suk Nam ${ }^{*}{ }^{\dagger}$, Ashish Ranjan Sharma ${ }^{\dagger}$ and Sang-Soo Lee * (D) \\ Institute for Skeletal Aging \& Orthopedic Surgery, Hallym University-Chuncheon Sacred Heart Hospital, \\ Chuncheon-si 24252, Gangwon-do, Korea; microbio.garima@gmail.com (G.S.); \\ boneresearch@hallym.ac.kr (A.R.S.) \\ * Correspondence: jsnam88@hallym.ac.kr (J.-S.N.); 123sslee@gmail.com (S.-S.L.); \\ Tel.: +82-33-248-3292 (J.-S.N.); +82-33-240-5197 (S.-S.L.); \\ Fax: +82-33-248-3293 (J.-S.N.); +82-33-252-0177 (S.-S.L.) \\ + These authors contributed equally to this work.
}

Academic Editors: Frederic Lesage and Ashok Kakkar

Received: 11 August 2018; Accepted: 5 September 2018; Published: 5 September 2018

\begin{abstract}
Coptidis rhizome contains several alkaloids that are bioactive agents of therapeutic value. We propose an eco-friendly method to synthesize biocompatible silver nanoparticles (AgNPs) using the aqueous extract of Coptidis rhizome. Silver ions were reduced to AgNPs using the aqueous extract of Coptidis rhizome, indicating that Coptidis rhizome can be used for the biosynthesis of AgNPs. The time and the concentration required for conversion of silver ions into AgNPs was optimized using UV-absorbance spectroscopy and inductively coupled plasma spectroscopy (ICP). Biosynthesized AgNPs showed a distinct UV-Visible absorption peak at $420 \mathrm{~nm}$. ICP analysis showed that the time required for the completion of biosynthesis was around $20 \mathrm{~min}$. Microscopic images showed that nanoparticles synthesized were of spherical shape and the average diameter of biosynthesized AgNPs was less than $30 \mathrm{~nm}$. XRD analysis also confirmed the size of AgNps and revealed their crystalline nature. The interaction of AgNPs with phytochemicals present in Coptidis rhizome extract was observed in FTIR analysis. The antimicrobial property of AgNPs was evaluated using turbidity measurements. Coptidis rhizome-mediated biosynthesized AgNPs showed significant anti-bacterial activities against Escherichia coli and Staphylococcus aureus that are commonly involved in various types of infections, indicating their potential as an effective anti-bacterial agent.
\end{abstract}

Keywords: silver nanoparticles; Coptidis rhizome; antibacterial; biosynthesis

\section{Introduction}

Recently, nanotechnology has emerged as a promising interdisciplinary section dealing with research and development in various fields [1,2]. The advancements of nanotechnology-based approaches in various commercial segments and their direct effect on human life justify the need for their ecofriendly ways of synthesis [3]. Nanoparticles are generally described as small particles that measures around $1 \mathrm{~nm}$ to $100 \mathrm{~nm}$ in size [4]. The variations in shape, size, surface to volume ratio, and composition of nanosized metal nanoparticle provides them unique physical, chemical, and biological properties, that can be used in medicines, electronics, household devices, agriculture, cosmetics, and pharmaceutical areas [5-10].

Metal nanoparticles are synthesized using various approaches, such as biological, physical, or chemical methods with the conditions to control the size/shape and stability of nanoparticles [11]. The distinctive advantages of biological synthesis of nanoparticles, over physical and chemical synthesis methods, include the non-toxic nature of the process, simple process design, and cost 
effectiveness [12]. Biological methods of metal nanoparticle synthesis are performed through intracellular or extracellular approaches, generally utilizing plants and microorganisms. The potential applications of these biosynthesized nanoparticles are shown in a wide spectrum of areas, including cancer treatment targeted drug delivery, DNA analysis, gene therapy, antibacterial agents, magnetic resonance imaging (MRI), enhancing reaction rates, and biosensors [13].

Plant-mediated nanoparticle synthesis, also known as "green synthesis", is the most widely acknowledged way of nanoparticle synthesis because of the plentiful and diversified cellular metabolites present in plant extracts [14]. These metabolites functions as bioactive compounds and are capable to act both as reducing and capping agents, thus eliminating the need to add any further chemical agent to synthesize the nanoparticles [14]. Recently, Vamanu et al. [15] showed the reduction of silver ions by phenolic compound homogentisic acid, which was present in the aqueous extract from Lactarius piperatus mushroom. The biodiversity of plants along with their phytochemical variations is the most accredited factor influencing the physical, chemical, and biological properties of biosynthesized nanoparticles as they generally get fabricated with nanoparticles during the synthesis progression.

Among metal nanoparticles, silver nanoparticles (AgNPs) are the most extensively studied nanomaterial. Silver has been used for ages as an excellent antimicrobial agent [16]. The conversion of silver into its nanoparticle form offers it unique physical and chemical properties that increases the efficacy of silver. AgNPs are used as disinfectant and as antimicrobial coating on medical instruments and devices, such as catheters $[17,18]$. Various mechanisms attributed to the antimicrobial activity shown by AgNPs, however, the exact mechanism is yet to be elucidated because the nanoparticles acts on different organisms in different ways. The development of antibiotic resistance by bacterial cells upon frequent use of antibiotics is a serious concern [19]. Recently, the promising antimicrobial potential of AgNPs against both gram positive and gram negative bacterial cells and their stability have attracted the scientific interest. Furthermore, by the use of AgNPs, the bacterial cells are less prone to develop antibacterial resistance [20].

Coptidis rhizome (Coptis chinensis Franch) has been known for its medicinal properties since ancient time. The dominant active compounds in aqueous extract of Coptidis rhizome include berberine, coptisine, jatrorrhizine, and palmatine. Coptidis rhizome has been well studied for its anti-diarrhea, anti-gastroenteritis, and chemotherapeutic properties [21,22]. However, the use of Coptidis rhizome for the biosynthesis of AgNPs is not reported. Here, we report Coptidis rhizome mediated eco-friendly ex-situ biosynthesis of AgNPs and the evaluation of their antimicrobial property against both Gram positive and Gram negative microorganisms.

\section{Results}

\subsection{UV-Visible Absorbance of Coptidis rhizome-Mediated Biosynthesized Silver Nanoparticles (bAgNPs)}

To observe the bioreduction potential of Coptidis rhizome extract and to optimize the required extract concentration for AgNPs synthesis, varying concentrations of plant extract $(5 \mathrm{~mL}, 10 \mathrm{~mL}, 20 \mathrm{~mL}$, and $30 \mathrm{~mL}$ ) were added to $100 \mathrm{~mL}$ of $\mathrm{AgNO}_{3}$ solution and UV-Visible spectra of colloidal reaction solution was monitored. Soon after the addition of all the extracts, the color of $\mathrm{AgNO}_{3}$ solution changed from transparent to yellow and then to stable dark brown color within 20 min (Figure 1). This color change was supposed to be due to the reduction of $\mathrm{AgNO}_{3}$ into AgNPs. The surface plasmon resonance (SPR) spectrum of bAgNPs produced by using Coptidis rhizome showed a distinct absorption peak at $420 \mathrm{~nm}$ (Figure 2a), confirming the presence of AgNPs. The intensity of the peak was lowest in $5 \mathrm{~mL}$ extract concentration solution while, it was maximum in reaction solutions with $20 \mathrm{~mL}$ and $30 \mathrm{~mL}$ of extracts. According to UV-Visible spectra, biosynthesis of AgNPs started immediately after the addition of extract as indicated by peak at $420 \mathrm{~nm}$ wavelength within $1 \mathrm{~min}$ of extract addition. Further, the intensity of UV-Visible spectra peak became almost stable after 20 min of reaction time suggesting the completion of AgNPs synthesis (Figure 2b). 
An absorption band at $280 \mathrm{~nm}$ observed in UV-Visible absorption spectra is plausibly attributed to electronic excitation in tryptophan and tyrosine residues in proteins [23]. This implies the presence of extracellular proteins in the colloidal solution and their possible mechanism in the bioreduction process [24].
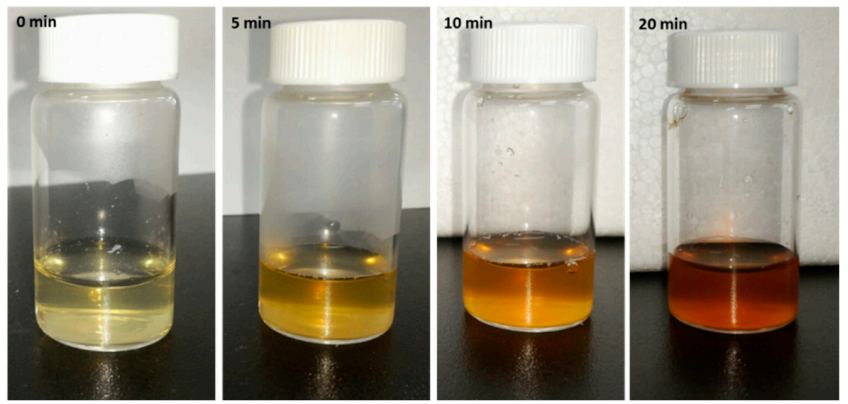

Figure 1. Time dependent variations in the colour of colloidal solution of silver nanoparticles synthesized using aqueous extract of Coptidis rhizome.

\subsection{Inductively Coupled Plasma (ICP) Spectroscopic Analysis of Coptidis rhizome-Mediated Biosynthesized Silver Nanoparticles (bAgNPs)}

The estimated time and extract concentration required for maximum bioreduction of Ag ions into zero valent AgNPs was further confirmed using ICP. As shown in Figure 2c, $5 \mathrm{~mL}$ and $10 \mathrm{~mL}$ of the extract concentration decreased approximately $30.38 \%$ and $51.21 \%$ of $\mathrm{Ag}$ ions, respectively, within $20 \mathrm{~min}$. However, $94 \%$ of $\mathrm{Ag}$ ions were reduced by $20 \mathrm{~mL}$ and $30 \mathrm{~mL}$ of extract concentrations within $20 \mathrm{~min}$ of reaction time. Therefore, the optimum extract concentration and time for maximum synthesis of AgNPs were estimated to be $20 \mathrm{~mL}$ and $20 \mathrm{~min}$, respectively.
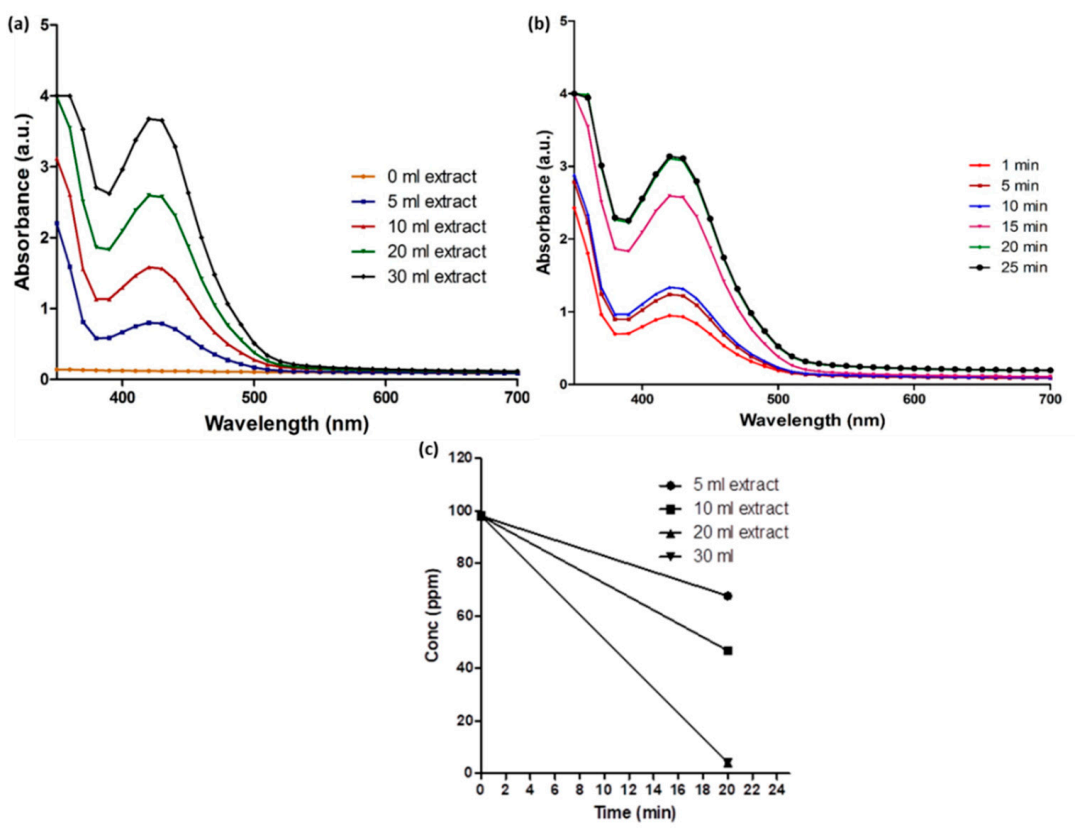

Figure 2. UV-Visible spectrum of Coptidis rhizome-mediated biosynthesized silver nanoparticles. (a) Surface plasmon resonance exhibited by biosynthesized silver nanoparticles using different concentration of Coptidis rhizome. (b) Surface plasmon resonance exhibited by biosynthesized silver nanoparticles at different time intervals. (c) Inductively coupled plasma graph of silver ions converted into zero valent form at different concentrations of Coptidis rhizome. 
2.3. X-ray Diffraction (XRD) Analysis of Coptidis rhizome-Mediated Biosynthesized Silver Nanoparticles (bAgNPs)

XRD study was performed to identify the crystalline structure of bAgNPs. Five intense diffraction peaks were observed at $38.14,44.31,64.48,77.42$, and 81.55 angles ( $2 \theta$ degree) which correspond to 111, 200, 220, 311, and 222 Bragg's reflection, respectively (Figure 3). These XRD peaks can be indexed as face-centered cubic silver (fcc), demonstrating high crystalline form of bAgNPs. These XRD peaks were also used to calculate the size of crystalline bAgNPs by Scherrer's equation.

$$
\mathrm{D}=\frac{0.94 \lambda}{\beta \cos \theta}
$$

where $D$ is the size of the nanoparticle, $\lambda$ is the wavelength, $\beta$ is the full width half maximum, and $\theta$ is the diffraction angle. According to different refraction peaks, the size of bAgNPs was calculated and is shown in Table 1. The results showed that average size of bAgNPs is $26.42 \mathrm{~nm}$.

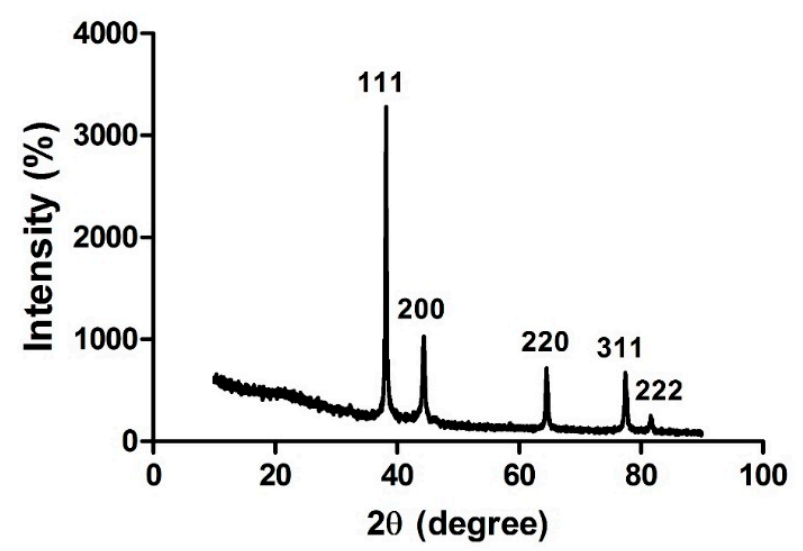

Figure 3. X-ray diffraction pattern of Coptidis rhizome-mediated biosynthesized silver nanoparticles.

Table 1. Average particle size of Coptidis rhizome-mediated biosynthesized AgNPs calculated using Scherrer's equation.

\begin{tabular}{ccc}
\hline Angle (20) & FWHM & Size \\
\hline 38.14 & 0.2747 & $29.6 \mathrm{~nm}$ \\
44.31 & 0.4471 & $19.1 \mathrm{~nm}$ \\
64.48 & 0.2736 & $35.5 \mathrm{~nm}$ \\
77.42 & 0.3946 & $25.8 \mathrm{~nm}$ \\
81.55 & 0.5220 & $22.1 \mathrm{~nm}$ \\
\hline
\end{tabular}

FWHM: full width and half maximum.

2.4. Transmission Electron Microscopic (TEM) Images of Coptidis rhizome-Mediated Biosynthesized Silver Nanoparticles (bAgNPs)

Additionally, the morphology and size of the bAgNPs were also examined by TEM. A representative TEM image showed that the Coptidis rhizome mediated bAgNPs were roughly spherical shape and evenly distributed in the sample (Figure 4). The observed nanoparticles in TEM image were in the range of $5 \mathrm{~nm}$ to $25 \mathrm{~nm}$ in diameter. 
a

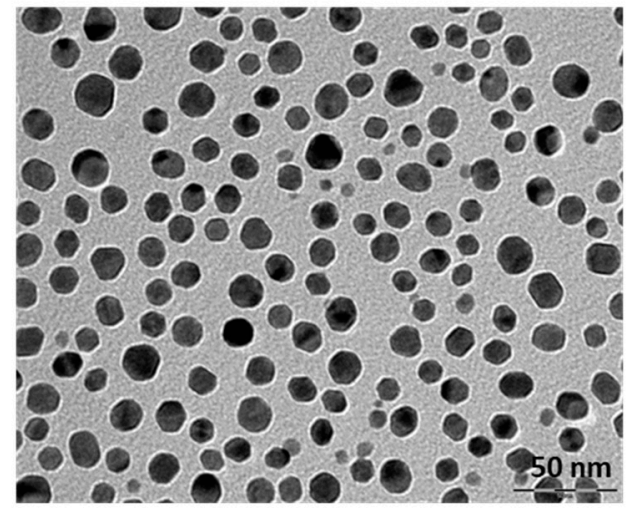

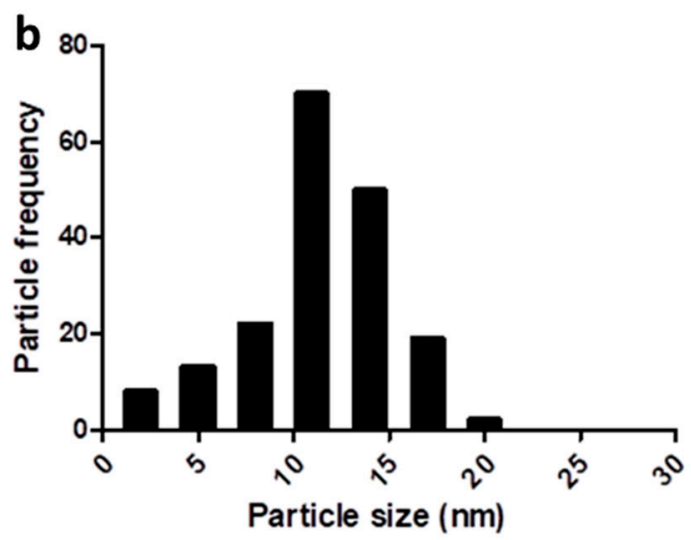

Figure 4. Transmission electron microscopic image of Coptidis rhizome-mediated biosynthesized silver nanoparticles. (a) Representative image. (b) Particle size histogram.

\subsection{Fourier Transform Infrared (FTIR) Spectrophotometric Analysis of Coptidis rhizome-Mediated} Biosynthesized Silver Nanoparticles (bAgNPs)

The possible interaction of bAgNPs and the phytochemicals present in Coptidis rhizome extract was determined using FTIR. These phytochemicals were presumed to act as stabilizing and reducing agents. Figure 5 shows the FTIR spectrum in the range of $400 \mathrm{~cm}^{-1}$ to $4000 \mathrm{~cm}^{-1}$ demonstrating varying peaks located at $3266 \mathrm{~cm}^{-1}, 2921 \mathrm{~cm}^{-1}, 1624 \mathrm{~cm}^{-1}, 1505 \mathrm{~cm}^{-1}, 1228 \mathrm{~cm}^{-1}, 1144 \mathrm{~cm}^{-1}, 1075 \mathrm{~cm}^{-1}$, and $999 \mathrm{~cm}^{-1}$.

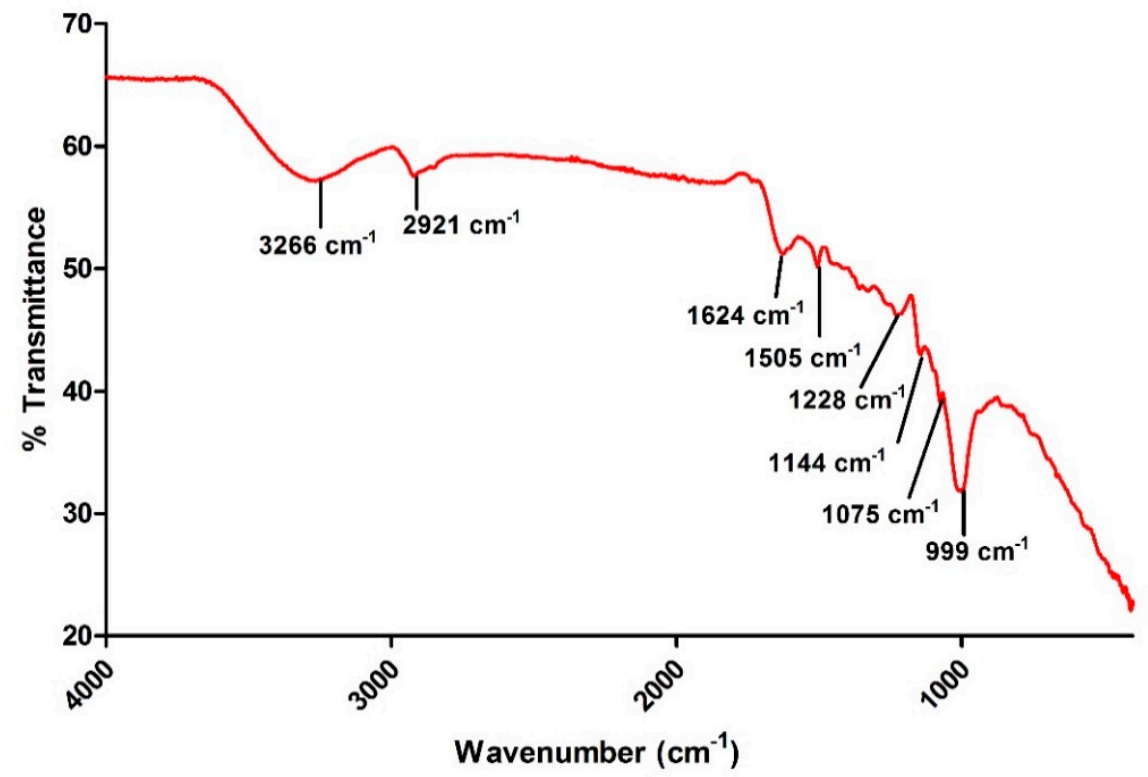

Figure 5. Fourier transform infrared spectrum of Coptidis rhizome-mediated biosynthesized silver nanoparticles.

\subsection{Antimicrobial Effect of Biosynthesized Silver Nanoparticles (bAgNPs)}

Here, turbidity measurements were used to evaluate the antimicrobial activity of bAgNPs against both Gram negative (E. coli) and Gram positive (S. aureus) microorganisms. Results showed dose dependent decrease in the bacterial growth upon treatment with bAgNPs. As compared to control, bAgNPs tend to increase the lag phase in bacterial growth curve of both the microorganisms at all the treated concentrations $(50,100$, and $150 \mu \mathrm{g} / \mathrm{mL}$ ) (Figure 6). It was observed that at high concentration 
$(150 \mu \mathrm{g} / \mathrm{mL})$, Coptidis rhizome-mediated bAgNPs completely inhibited the growth of E. coli until almost $12 \mathrm{~h}$. Furthermore, the results also showed that the antimicrobial effect of bAgNPs was stronger against E. coli than to $S$. aureus.
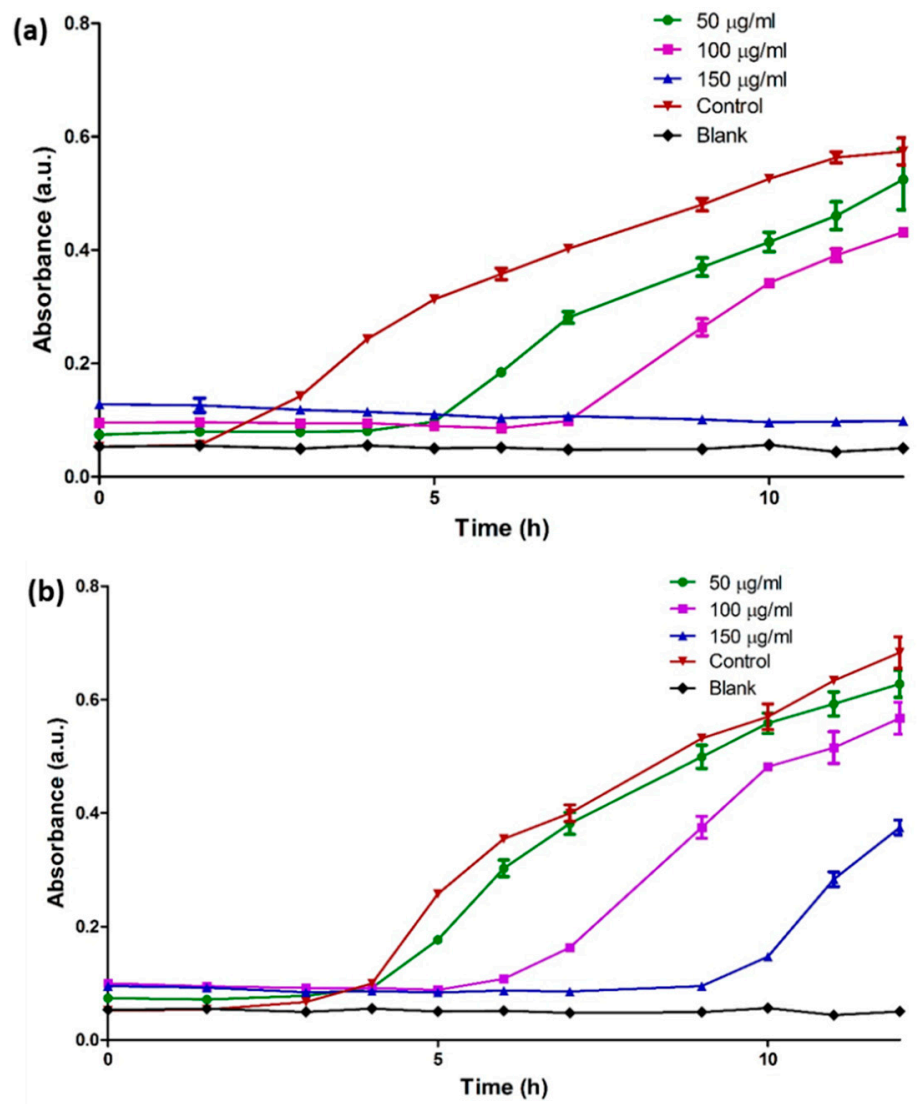

Figure 6. Antimicrobial study of Coptidis rhizome-mediated biosynthesized silver nanoparticles. (a) Escherichia coli (b) Staphylococcus aureus.

\section{Discussion}

Nowadays, plant-assisted biosynthesis of metal nanoparticles has been extensively studied as an eco-friendly and efficient way to exploit biomolecules of plants as convenient bio-reducing agents [25]. In this study, within 20 min of the exposure of Coptidis rhizome extract, the color of $\mathrm{AgNO}_{3}$ solution changed from transparent to dark brown color which is a primary indication of AgNPs production (Figure 1). The color change was in agreement to previously reported studies that demonstrated the appearance of brown color due to excitation of surface plasmon vibrations with the synthesized AgNPs [26,27]. Furthermore, the production of bAgNPs was confirmed by UV-Visible spectroscopic analysis which quantifies the absorption spectra produced due to collective excitation of conduction electrons in silver (Figure 2). In this study, the UV-Visible spectra of colloidal reaction solution showed a sharp characteristic peak at around $420 \mathrm{~nm}$ wavelength which was produced due to SPR [28]. The optical absorption spectra of metallic nanoparticles are predominantly dominated by SPR and the peak of absorption correlated with particle size [29]. The shifting of the SPR peak of AgNPs in aqueous dispersion towards longer wavelengths is associated with the increase in particle size. Previous studies showed the effect of nanoparticle size, shape, and dielectric environment on the SPR band of noble metal nanoparticles [30,31]. Time dependent UV-Visible spectra analysis showed that maximum bioreduction was done within 20 min of reaction time which was further confirmed by ICP analysis (98\%). 
Although the exact mechanism of plant extract-mediated silver nanoparticle biosynthesis is not fully elucidated, some potential mechanisms have been proposed to explain the biosynthesis phenomenon [11]. It has been proposed that the presence of cellular enzymes in the plant extract can efficiently reduce silver ions into silver nanoparticles [11]. Besides reducing enzymes, other phytochemicals can also reduce silver ions into SNPs and can also act as capping agents to prevent nanoparticle aggregation $[3,5]$.

The biosynthesis of crystalline AgNPs was confirmed by XRD spectrum which demonstrated peaks at $2 \theta$ of $38.14,44.31,64.48,77.42$, and 81.55 corresponding to 111, 200, 220, 311, and 222 facecentered cubic crystallographic planes of silver crystals (Figure 3). The results were in agreement to JCPDS card file no. 01-087-0717 [32]. The similar reflection peaks were reported in the Ocimum sanctum-mediated synthesized silver nanoparticles [14]. Additionally, the average size of bAgNPs was also calculated using Scherrer's formula [33], which was $26.42 \mathrm{~nm}$. Therefore, it can be assumed that phytochemicals present in the aqueous extract of Coptidis rhizome served as reducing agent during the AgNPs biosynthesis process.

Additionally, TEM images revealed the absence of aggregated nanoparticle clusters showing evenly distributed spherical bAgNPs in the sample (Figure 4). Thus, TEM images suggest that the phytochemicals present in Coptidis rhizome extract may serve as capping agents. The size of bAgNPs as shown in the TEM image was in the range of approximately 5 to $25 \mathrm{~nm}$ which was similar to the average size obtained by XRD analysis. The size of nanoparticles observed in TEM images was in accordance with previous reports $[33,34]$. Size and shape of nanoparticles are important factors affecting their biological properties [35].

The FT-IR spectra showed a broad absorption peak at $3266 \mathrm{~cm}^{-1}$ which may be attributed to hydroxyl $(\mathrm{O}-\mathrm{H})$ group of deionized water [36]. The presence of $\mathrm{C}-\mathrm{H}$ stretching of aromatic compound was also ascertained by the absorption peak at $2921 \mathrm{~cm}^{-1}$ [37]. Additionally, the peaks at $1624 \mathrm{~cm}^{-1}$ and $1505 \mathrm{~cm}^{-1}$ are ascribed to $-\mathrm{C}=\mathrm{C}-$ and $=\mathrm{NH}$ stretching of amide bonds, respectively [38]. This indicated that the amino groups are involved in the encapsulation and stabilization of bAgNPs. According to a previous study, absorption peak at $1505 \mathrm{~cm}^{-1}$ corresponds to flavonoids signifying the role of flavonoids in the bioreduction of silver ions into AgNPs [39]. Terpenoids associated ether linkages are also suggested in the Coptidis rhizome-mediated bAgNPs due to the presence of absorption peak at $1228 \mathrm{~cm}^{-1}$ [40]. Carbonyl (C-OH) stretching of proteins at $1075 \mathrm{~cm}^{-1}$ was also observed in FTIR spectra [41]. Henceforth, the FTIR peaks obtained here showed the presence of various phytochemicals, including flavonoids, terpenoids, and proteins, in the aqueous extract of Coptidis rhizome. Furthermore, FTIR indicates the multi-functionality of Coptidis rhizome in the bioreduction and stabilization of AgNPs (Figure 5).

Here, turbidity measurement were carried out to evaluate the antimicrobial potential of biogenic AgNPs against E. coli (gram negative) and S. aureus (gram positive) bacterial cells. The results demonstrate extended lag phase which suggests dose dependent antibacterial effect of bAgNPs on both Gram positive and Gram negative microorganisms in consistence to previous studies [14]. Various mechanistic approaches detailing biochemical, physiological and morphological effect of AgNPs on bacterial cells were proposed in previous studies. Li et al., demonstrated that AgNPs may cause damage to E. coli cell membrane and interferes with the function of membrane enzymes eventually leading to cell death [42]. Generation of oxidative stress and production of reactive oxygen species (ROS), possibly due to inhibition of respiratory enzyme, was also attributed to bacterial cell death in some studies [43,44]. Electron spin resonance spectroscopy studies showed that the uncontrolled generation of free radicals from AgNPs can bind to membrane lipids rendering porosity to the cell membrane, leading to impaired membrane functions and cell death [45]. Preferential binding of AgNPs to phosphorous containing molecules, such as DNA, has also been revealed that may cause impaired DNA replication in the microbes [46].

Silver salts have been used as antimicrobial agents for decades. Monodispersed small sized spherical nanoparticles provide a higher surface area that enhances the antibacterial potential of silver. 
In fact, the size-dependent interaction of SNPs with pathogenic bacteria and viruses has been reported by many authors $[47,48]$. Aqueous extract of Coptidis rhizome is also well known for its antimicrobial effect, indicating the presence of biomolecules that possess antibacterial potential [49]. In line with previous study [50], it is possible that the capping biomolecules present on Coptidis rhizome-mediated bAgNPs might contribute to the antibacterial effect of nanoparticles. However, the exact mechanism of AgNPs-induced antibacterial effect is still unclear.

\section{Materials and Methods}

\subsection{Materials}

The dried rhizome of Coptidis rhizome (Coptis chinensis Franch) was purchased from Hanyagin Co., Ltd. (Youngcheon, Korea) as an oriental medicine. Silver nitrate $\left(\mathrm{AgNO}_{3}\right)$ used in this study was purchased from Sigma, Aldrich, St. Louis, MO, USA.

\subsection{Preparation of Plant Extract}

Plant extract was prepared as previously described with modifications [14]. The collected plant rhizome was washed twice with distilled water and then air dried in dark at room temperature (RT). Afterwards, the plant part was grounded to powder using electric grinder. To prepare the extract, $10 \mathrm{~g}$ of the ground powder was added to $100 \mathrm{~mL}$ of distilled water at $60{ }^{\circ} \mathrm{C}$ under stirring for $60 \mathrm{~min}$. The solution was then centrifuged at 12,000 rpm for $15 \mathrm{~min}$ in refrigerated centrifuge (Combi 514R, Hanil, Korea) to remove the debris as pellet. The plant extract was collected as supernatant and was stored at $4{ }^{\circ} \mathrm{C}$ for further use.

\subsection{Biosynthesis of Silver Nanoparticles (AgNPs)}

The Coptidis rhizome extract was used for the bioreduction of $\mathrm{AgNO}_{3}$ into $\mathrm{AgNPs}$. Briefly, for biosynthesis of AgNPs, various concentrations of Coptidis rhizome aqueous extract was added to $1 \mathrm{mM}$ of $\mathrm{AgNO}_{3}$ at $40{ }^{\circ} \mathrm{C}$ and the reaction mixture was further stirred till the reaction mixture exhibited a stable color change to dark brown. The biosynthesized silver nanoparticle (bAgNPs) containing solution was then centrifuged at 13,000 rpm for $30 \mathrm{~min}$ in a refrigerated centrifuge (Combi 514R, Hanil, Korea) to purify bAgNPs as pellet. The collected bAgNPs were washed thrice with deionized and double distilled water to remove the silver ions and the remains of unbounded phytochemicals present along with nanoparticles. Finally, the purified bAgNPs were lyophilized and stored at $4{ }^{\circ} \mathrm{C}$ as powder for further experiments [3].

\subsection{UV-Visible Absorbance Spectroscopy}

To examine the reduction of Ag ions into AgNPs, aliquots of the reaction solution were studied for the optical property of bAgNPs by measuring UV-Visible spectrum at a resolution of $10 \mathrm{~nm}$ from $200 \mathrm{~nm}$ to $800 \mathrm{~nm}$ at RT using UV-Visible spectroscopy (SpectraMax M2e Multi-Mode Microplate Reader, Molecular Devices, LLC, San Jose, CA, USA) [14].

\subsection{Inductively Coupled Plasma (ICP) Spectroscopy}

To confirm the conversion of Ag ions into zero valent AgNPs, the concentration of Ag ions in the reaction solution was measured using inductively coupled plasma spectroscopy (ICP-OES, ICAP 6300 duo thermo scientific). In brief, aliquots of reaction solution were withdrawn and centrifuged at 12,000 rpm for $15 \mathrm{~min}$ to separate non-ionic AgNPs as pellet. The Ag ions present in the supernatant were further quantified using ICP and the percent reduction of $\mathrm{AgNO}_{3}$ into $\mathrm{AgNPs}$ was calculated using following formula [51].

$$
\% \text { conversion }=\left(\frac{C i-C f}{C i}\right) \times 100
$$


where, $C i$ and $C f$ are initial concentration and final concentration, respectively.

\subsection{Transmission Electron Microscopy (TEM)}

The morphology and size of bAgNPs was determined using high resolution transmission electron microscopy (TEM; JEM-2100F, JEOL, Tokyo, Japan). For this, bAgNPs were dispersed in double distilled water and sonicated for around $20 \mathrm{~min}$. A drop of sonicated sample of bAgNPs was then loaded onto carbon coated copper grid. After evaporating the excess solvent, bAgNPs were visualized using TEM which was operated at accelerating voltage of 0-30 kV [14].

\subsection{Fourier-Transform Infrared (FTIR) Spectroscopic Analysis}

The vibrational bonding between the bAgNPs and phyto-molecules attached on their surface were analyzed using Fourier transform infrared spectrophotometer (FT-IR) with attenuated total reflectance (ATR) crystal (Perkin Elmer, Waltham, MA, USA). The FT-IR spectrum was recorded in the range of $400-4000 \mathrm{~cm}^{-1}$ with $4 \mathrm{~cm}^{-1}$ spectral resolution [14].

\subsection{X-ray Diffraction (XRD) Analysis}

XPERT-PRO diffractometer was used to perform X-ray diffraction (XRD) measurements of Coptidis rhizome mediated biologically synthesized AgNPs. In brief, AgNPs were casted onto glass slides and were analyzed in X-ray diffractometer operating at $\mathrm{Cu}-\mathrm{K}(\alpha)$ radiation of $1.5418 \AA$ wavelength, $40 \mathrm{kV}$ voltage, and $30 \mathrm{~mA}$ current. The scanning was done in the $2 \theta$ range from $10^{\circ}$ to $90^{\circ}$ [3].

\subsection{Antimicrobial Studies}

Antimicrobial activity of bAgNPs was determined as previously described by Okafor et al. [52]. The bAgNPs were prepared as previously described. To minimize the possibility of additive antimicrobial effect of Coptidis rhizome extract, nanoparticles were washed three times with D/W to remove extract and unbound biomolecules. For antimicrobial assays, the purified bAgNPs were first dispersed in autoclaved deionized water with the help of ultrasonicator to prepare a stock solution. Various concentrations of dispersed AgNPs were then prepared from the stock solution for the treatment. Microbial cultures (Escherichia coli ATCC 25922 and Staphylococcus aureus ATCC 29213) were grown in autoclaved nutrient broth medium which was prepared by adding $\mathrm{NaCl}(5 \mathrm{~g} / \mathrm{L})$, peptone $(5 \mathrm{~g} / \mathrm{L})$, and beef extract $(3 \mathrm{~g} / \mathrm{L})$ in deionized distilled water. Stock cultures of Escherichia coli and Staphylococcus aureus were then inoculated separately in the nutrient broth medium and incubated overnight. Afterwards, $15 \mu \mathrm{L}$ of overnight bacterial cultures were added separately to each flask containing $15 \mathrm{~mL}$ of nutrient broth. The as-prepared microbial suspensions were treated with different concentrations of dispersed Coptidis rhizome mediated bAgNPs. Flasks were kept in incubator shaker at $150 \mathrm{rpm} / \mathrm{min}$ at $37^{\circ} \mathrm{C}$ for $24 \mathrm{~h}$. Blank nutrient broth was taken as control. At pre-determined time points, aliquots from all the treatment flasks were observed for bacterial growth using UV-Vis spectrophotometer at $600 \mathrm{~nm}$ wavelength.

\section{Conclusions}

The present study concludes a successful and rapid biogenic process for AgNPs synthesis using aqueous extract of Coptidis rhizome. Phytochemicals present in the extract served as efficient bio-reducing and capping agents. Furthermore, this study also described the antimicrobial potential of biogenic AgNPs against bacterial cells, suggesting its application as an efficient antimicrobial agent in the future. However, the detailed mechanisms of antibacterial action are yet to be uncovered in future studies.

Author Contributions: G.S. and J.-S.N. designed this study. G.S. and A.R.S. conducted the study and wrote the manuscript. J.-S.N. and S.-S.L. analyzed the data. 
Funding: This research was supported by Hallym University Research Fund, by Basic Science Research Program through the National Research Foundation of Korea (NRF) funded by the Ministry of Education (NRF-2016R1D1A1B03931318 and NRF-2017R1A2B4012944).

Conflicts of Interest: The authors declare no conflict of interest.

\section{References}

1. Dubas, S.T.; Pimpan, V. Humic acid assisted synthesis of silver nanoparticles and its application to herbicide detection. Mater. Lett. 2008, 62, 2661-2663. [CrossRef]

2. Xu, X.; Yang, Q.; Bai, J.; Lu, T.; Li, Y.; Jing, X. Fabrication of biodegradable electrospun poly(L-lactideco-glycolide) fibers with antimicrobial nanosilver particles. J. Nanosci. Nanotechnol. 2008, 8, 5066-5070. [CrossRef] [PubMed]

3. Sharma, G.; Sharma, A.R.; Bhavesh, R.; Park, J.; Ganbold, B.; Nam, J.S.; Lee, S.S. Biomolecule-mediated synthesis of selenium nanoparticles using dried Vitis vinifera (raisin) extract. Molecules 2014, 19, 2761-2770. [CrossRef] [PubMed]

4. Mude, N.; Ingle, A.; Gade, A.; Rai, M. Synthesis of silver nanoparticles using callus extract of Carica papaya-A first report. J. Plant Biochem. Biotechnol. 2009, 18, 83-86. [CrossRef]

5. Vivek, R.; Thangam, R.; Muthuchelian, K.; Gunasekaran, P.; Kaveri, K.; Kannan, S. Green biosynthesis of silver nanoparticles from Annona squamosa leaf extract and its in vitro cytotoxic effect on MCF-7 cells. Process Biochem. 2012, 47, 2405-2410. [CrossRef]

6. Ko, S.H.; Park, I.; Pan, H.; Grigoropoulos, C.P.; Pisano, A.P.; Luscombe, C.K.; Fréchet, J.M.J. Direct nanoimprinting of metal nanoparticles for nanoscale electronics fabrication. Nano Lett. 2007, 7, 1869-1877. [CrossRef] [PubMed]

7. Yan, H.; Melosh, N. Electronic devices: Nanoparticles make salty circuits. Nat. Nano 2016, 11, 579-580. [CrossRef] [PubMed]

8. Sekhon, B.S. Nanotechnology in agri-food production: An overview. Nanotechnol. Sci. Appl. 2014, 7, 31-53. [CrossRef] [PubMed]

9. Kokura, S.; Handa, O.; Takagi, T.; Ishikawa, T.; Naito, Y.; Yoshikawa, T. Silver nanoparticles as a safe preservative for use in cosmetics. Nanomedicine 2010, 6, 570-574. [CrossRef] [PubMed]

10. Salata, O.V. Applications of nanoparticles in biology and medicine. J. Nanobiotechnol. 2004, 2, 3. [CrossRef] [PubMed]

11. Iravani, S.; Korbekandi, H.; Mirmohammadi, S.V.; Zolfaghari, B. Synthesis of silver nanoparticles: Chemical, physical and biological methods. Res. Pharm. Sci. 2014, 9, 385-406. [PubMed]

12. Singh, P.; Kim, Y.-J.; Zhang, D.; Yang, D.-C. Biological synthesis of nanoparticles from plants and microorganisms. Trends Biotechnol. 2016, 34, 588-599. [CrossRef] [PubMed]

13. Heydari, R. Biological applications of biosynthesized silver nanoparticles through the utilization of plant extracts. Herb. Med. J. 2017, 2, 87-95.

14. Singhal, G.; Bhavesh, R.; Kasariya, K.; Sharma, A.R.; Singh, R.P. Biosynthesis of silver nanoparticles using Ocimum sanctum (Tulsi) leaf extract and screening its antimicrobial activity. J. Nanopart. Res. 2011, 13, 2981-2988. [CrossRef]

15. Vamanu, E.; Ene, M.; Bita, B.; Lonescu, C.; Cracium, L.; Sarbu, L. In vitro human microbiota response to exposure to silver nanoparticles biosynthesized with mushroom extract. Nutrients 2018, 10, 607. [CrossRef] [PubMed]

16. Clement, J.L.; Jarrett, P.S. Antibacterial silver. Met. Based Drugs 1994, 1, 467-482. [CrossRef] [PubMed]

17. Zhao, L.; Wang, H.; Huo, K.; Cui, L.; Zhang, W.; Ni, H.; Zhang, Y.; Wu, Z.; Chu, P.K. Antibacterial nano-structured titania coating incorporated with silver nanoparticles. Biomaterials 2011, 32, 5706-5716. [CrossRef] [PubMed]

18. Jo, Y.K.; Seo, J.H.; Choi, B.H.; Kim, B.J.; Shin, H.H.; Hwang, B.H.; Cha, H.J. Surface-independent antibacterial coating using silver nanoparticle-generating engineered mussel glue. ACS Appl. Mater. Interfaces 2014, 6, 20242-20253. [CrossRef] [PubMed]

19. Zhao, L.; Chu, P.K.; Zhang, Y.; Wu, Z. Antibacterial coatings on titanium implants. J. Biomed. Mater. Res. B Appl. Biomater. 2009, 91, 470-480. [CrossRef] [PubMed] 
20. Rai, M.; Yadav, A.; Gade, A. Silver nanoparticles as a new generation of antimicrobials. Biotechnol. Adv. 2009, 27, 76-83. [CrossRef] [PubMed]

21. Iizuka, N.; Miyamoto, K.; Okita, K.; Tangoku, A.; Hayashi, H.; Yosino, S.; Abe, T.; Morioka, T.; Hazama, S.; Oka, M. Inhibitory effect of Coptidis Rhizoma and berberine on the proliferation of human esophageal cancer cell lines. Cancer Lett. 2000, 148, 19-25. [CrossRef]

22. Fukutake, M.; Yokota, S.; Kawamura, H.; Iizuka, A.; Amagaya, S.; Fukuda, K.; Komatsu, Y. Inhibitory effect of Coptidis Rhizoma and Scutellariae Radix on azoxymethane-induced aberrant crypt foci formation in rat colon. Biol. Pharm. Bull. 1998, 21, 814-817. [CrossRef] [PubMed]

23. Eftink, M.R.; Ghiron, C.A. Fluorescence quenching studies with proteins. Anal. Biochem. 1981, 114, $199-227$. [CrossRef]

24. Fayaz, A.M.; Balaji, K.; Girilal, M.; Yadav, R.; Kalaichelvan, P.T.; Venketesan, R. Biogenic synthesis of silver nanoparticles and their synergistic effect with antibiotics: A study against gram-positive and gram-negative bacteria. Nanomedicine 2010, 6, 103-109. [CrossRef] [PubMed]

25. Kumar Sur, U.; Ankamwar, B.; Karmakar, S.; Halder, A.; Das, P. Green synthesis of silver nanoparticles using the plant extract of shikakai and reetha. Mater. Today 2018, 5, 2321-2329. [CrossRef]

26. Balaji, D.S.; Basavaraja, S.; Deshpande, R.; Mahesh, D.B.; Prabhakar, B.K.; Venkataraman, A. Extracellular biosynthesis of functionalized silver nanoparticles by strains of Cladosporium cladosporioides fungus. Colloids Surf. B Biointerfaces 2009, 68, 88-92. [CrossRef] [PubMed]

27. Mulvaney, P. Surface Plasmon Spectroscopy of Nanosized Metal Particles. Langmuir 1996, 12, 788-800. [CrossRef]

28. Sunkar, S.; Nachiyar, C.V. Biogenesis of antibacterial silver nanoparticles using the endophytic bacterium Bacillus cereus isolated from Garcinia xanthochymus. Asian Pac. J. Trop. Biomed. 2012, 2, 953-959. [CrossRef]

29. Brause, R.; Möltgen, H.; Kleinermanns, K. Characterization of laser-ablated and chemically reduced silver colloids in aqueous solution by UV/VIS spectroscopy and STM/SEM microscopy. Appl. Phys. B Lasers Opt. 2002, 75, 711-716. [CrossRef]

30. Kelly, K.L.; Coronado, E.; Zhao, L.L.; Schatz, G.C. The optical properties of metal nanoparticles: The influence of size, shape, and dielectric environment. J. Phys. Chem. B 2003, 107, 668-677. [CrossRef]

31. Krishnaraj, C.; Jagan, E.G.; Rajasekar, S.; Selvakumar, P.; Kalaichelvan, P.T.; Mohan, N. Synthesis of silver nanoparticles using Acalypha indica leaf extracts and its antibacterial activity against water borne pathogens. Colloids Surf. B Biointerfaces 2010, 76, 50-56. [CrossRef] [PubMed]

32. Velusamy, P.; Su, C.H.; Venkat Kumar, G.; Adhikary, S.; Pandian, K.; Gopinath, S.C.; Chen, Y.; Anbu, P. Biopolymers regulate silver nanoparticle under microwave irradiation for effective antibacterial and antibiofilm activities. PLOS ONE 2016, 11, e0157612. [CrossRef] [PubMed]

33. Logeswari, P.; Silambarasan, S.; Abraham, J. Synthesis of silver nanoparticles using plants extract and analysis of their antimicrobial property. J. Saudi Chem. Soc. 2015, 19, 311-317. [CrossRef]

34. Abdullah, N.I.; Ahmad, M.B.; Shameli, K. Biosynthesis of silver nanoparticles using Artocarpus elasticus stem bark extract. Chem. Central J. 2015, 9, 61. [CrossRef] [PubMed]

35. Anwar, M.F.; Yadav, D.; Jain, S.; Kapoor, S.; Rastogi, S.; Arora, I.; Samim, M. Size- and shape-dependent clinical and mycological efficacy of silver nanoparticles on dandruff. Int. J. Nanomed. 2016, 11, 147-161.

36. Zafar, N.; Shamaila, S.; Nazir, J.; Sharif, R.; Shahid Rafique, M.; Ul-Hasan, J.; Ammara, S.; Khalid, H. Antibacterial action of chemically synthesized and laser generated silver nanoparticles against human pathogenic bacteria. J. Mater. Sci. Technol. 2016, 32, 721-728. [CrossRef]

37. Jyoti, K.; Baunthiyal, M.; Singh, A. Characterization of silver nanoparticles synthesized using Urtica dioica Linn. leaves and their synergistic effects with antibiotics. J. Radiat. Res. Appl. Sci. 2016, 9, 217-227. [CrossRef]

38. Satyavani, K.; Gurudeeban, S.; Ramanathan, T.; Balasubramanian, T. Biomedical potential of silver nanoparticles synthesized from calli cells of Citrullus colocynthis (L.) Schrad. J. Nanobiotechnol. 2011, 9, 43. [CrossRef]

39. Cheng, H.L.; Zhang, L.J.; Liang, Y.H.; Hsu, Y.W.; Lee, I.J.; Liaw, C.C.; Hwang, S.Y.; Kuo, Y.H. Antiinflammatory and antioxidant flavonoids and phenols from Cardiospermum halicacabum (Dao Di Ling). J. Tradit. Complement Med. 2013, 3, 33-40. [CrossRef]

40. Arunachalam, R.; Dhanasingh, S.; Kalimuthu, B.; Uthirappan, M.; Rose, C.; Mandal, A.B. Phytosynthesis of silver nanoparticles using Coccinia grandis leaf extract and its application in the photocatalytic degradation. Colloids Surf. B Biointerfaces 2012, 94, 226-230. [CrossRef] [PubMed] 
41. Wang, L.S.; Wang, C.Y.; Yang, C.H.; Hsieh, C.L.; Chen, S.Y.; Shen, C.Y.; Wang, J.J.; Huang, K.S. Synthesis and anti-fungal effect of silver nanoparticles-chitosan composite particles. Int. J. Nanomed. 2015, 10, 2685-2696.

42. Li, W.R.; Xie, X.B.; Shi, Q.S.; Zeng, H.Y.; Ou-Yang, Y.S.; Chen, Y.B. Antibacterial activity and mechanism of silver nanoparticles on Escherichia coli. Appl. Microbiol. Biotechnol. 2010, 85, 1115-1122. [CrossRef] [PubMed]

43. Carlson, C.; Hussain, S.M.; Schrand, A.M.; Braydich-Stolle, L.K.; Hess, K.L.; Jones, R.L.; Schlager, J.J. Unique cellular interaction of silver nanoparticles: Size-dependent generation of reactive oxygen species. J. Phys. Chem. B 2008, 112, 13608-13619. [CrossRef] [PubMed]

44. Das, B.; Dash, S.K.; Mandal, D.; Ghosh, T.; Chattopadhyay, S.; Tripathy, S.; Das, S.; Dey, S.K.; Das, D.; Roy, S. Green synthesized silver nanoparticles destroy multidrug resistant bacteria via reactive oxygen species mediated membrane damage. Arab. J. Chem. 2017, 10, 862-876. [CrossRef]

45. Kim, J.S.; Kuk, E.; Yu, K.N.; Kim, J.-H.; Park, S.J.; Lee, H.J.; Kim, S.H.; Park, Y.K.; Park, Y.H.; Hwang, C.-Y.; et al. Antimicrobial effects of silver nanoparticles. Nanomedicine 2007, 3, 95-101. [CrossRef] [PubMed]

46. Chen, M.; Yang, Z.; Wu, H.; Pan, X.; Xie, X.; Wu, C. Antimicrobial activity and the mechanism of silver nanoparticle thermosensitive gel. Int. J. Nanomed. 2011, 6, 2873-2877.

47. Xu, X.N.; Brownlow, W.J.; Kyriacou, S.V.; Wan, Q.; Viola, J.J. Real-time probing of membrane transport in living microbial cells using single nanoparticle optics and living cell imaging. Biochemistry 2004, 43, 10400-10413. [CrossRef] [PubMed]

48. Gogoi, S.K.; Gopinath, P.; Paul, A.; Ramesh, A.; Ghosh, S.S.; Chattopadhyay, A. Green fluorescent protein-expressing Escherichia coli as a model system for investigating the antimicrobial activities of silver nanoparticles. Langmuir 2006, 22, 9322-9328. [CrossRef] [PubMed]

49. Feng, X.; Yan, D.; Zhao, K.J.; Luo, J.Y.; Ren, Y.S.; Kong, W.J.; Han, Y.M.; Xiao, X.H. Applications of microcalarorimetry in the antibacterial activity evaluation of various Rhizoma coptidis. Pharma. Biol. 2011, 49, 348-353. [CrossRef] [PubMed]

50. Vankar, P.S.; Shukla, D. Biosynthesis of silver nanoparticles using lemon leaves extract and its application for antimicrobial finish on fabric. Appl. Nanosci. 2012, 2, 163-168. [CrossRef]

51. Pandey, S.; Mewada, A.; Thakur, M.; Shinde, S.; Shah, R.; Oza, G.; Sharon, M. Rapid biosynthesis of silver nanoparticles by exploiting the reducing potential of Trapa bispinosa peel extract. J. Nanosci. 2013, 2013, 1-9. [CrossRef]

52. Okafor, F.; Janen, A.; Kukhtareva, T.; Edwards, V.; Curley, M. Green synthesis of silver nanoparticles, their characterization, application and antibacterial activity. Int J. Environ. Res. Public Health 2013, 10, 5221-5238. [CrossRef] [PubMed]

Sample Availability: Samples of the compounds are available from the authors.

(C) 2018 by the authors. Licensee MDPI, Basel, Switzerland. This article is an open access article distributed under the terms and conditions of the Creative Commons Attribution (CC BY) license (http:/ / creativecommons.org/licenses/by/4.0/). 